\title{
Apathy and Emotional Blunting in Parkinson's Disease
}

\author{
Iracema Leroi ${ }^{1,2^{*}}$, Nilika Perera ${ }^{2}$, Vijay Harbishettar ${ }^{3,4}$ and Philippe Robert ${ }^{5}$ \\ ${ }^{1}$ Manchester Mental Health and Social Care Trust, UK \\ ${ }^{2}$ Manchester Health Sciences Centre, UK \\ ${ }^{3}$ South Essex Partnership University NHS Trust, UK \\ ${ }^{4}$ University of Leeds, UK \\ ${ }^{5}$ CoBTeK \& Memory Centre, University of Nice Sophia, Antipolis, France
}

"Corresponding author: Iracema Leroi MD FRCPC MRC Psych, Clinical Senior Lecturer/Honorary Consultant in Psychiatry/Dementia Director DeNDRoN NW, University of Manchester/Manchester Mental Health and Social Care Trust, Institute of Brain, Behaviour and Mental Health, Jean McFarlane Building, 3rd Floor, Oxford Rd, Manchester, UK, Tel: +44 7758754813; E-mail: Iracema.Leroi@manchester.ac.uk

Received date: Jul 29, 2014, Accepted date: Aug 18, 2014, Published date: Aug 28, 2014

Copyright: ( 2014 Leroi I, et al. This is an open-access article distributed under the terms of the Creative Commons Attribution License, which permits unrestricted use, distribution, and reproduction in any medium, provided the original author and source are credited.

\begin{abstract}
Background: Apathy is common in Parkinson's disease (PD), even in the absence of dementia. In general, apathy has three key dimensions: emotional blunting, diminished initiative, and diminished interest. The objective of this study was to evaluate the clinical profile and impact of apathy in PD with particular emphasis on emotional blunting.

Methods: 91 PD participants free of dementia were evaluated with the Apathy Inventory (IA). Those with clinically significant apathy $(n=32)$ were compared to those without apathy $(n=59)$ on clinical variables, level of disability, quality of life and caregiver burden. Within the apathy group, a subsequent comparison of those with apathy and emotional blunting $(E B+; n=22)$ to those with apathy but no blunting $(E B-; n=10)$ was undertaken.
\end{abstract}

Results: In PD, compared to those without apathy, apathy sufferers were significantly more depressed, and had more impaired executive function, quality of life, and greater disability and caregiver burden. The EB+ group had worse quality of life and greater caregiver burden compared to the EB- group despite the EB- group being associated with older age and more advanced disease.

Conclusion: In PD without dementia, apathy with emotional blunting has a greater adverse impact on the affected person and their caregiver than apathy without emotional blunting.

Keywords: Parkinson's disease; Apathy, Apathy inventory; Executive dysfunction; Initiative; Interest; Emotional blunting

\section{Introduction}

Apathy is increasingly recognised as an important behavioural complication that can affect the majority of people with idiopathic Parkinson's disease (PD), both with and without dementia . In PD, apathy has been shown to impact significantly on quality of life (QoL), caregiver burden and disability. Furthermore, the presence of apathy may predict conversion to dementia [1-3]. Apathy is generally considered a syndrome that can be understood as a quantitative reduction in goal-directed behaviour in several dimensions: (a) diminished or blunted emotions; (b) loss of or diminished initiative; and (c) loss of or diminished interest [4].

Apathy has multiple underlying pathologies which will differ depending on which of the dimensions have manifested in the clinical syndrome [5,6]. For example, reduction or loss of interest and initiative, or "cognitive inertia" may be related to deficits in executive function driven by the dorsolateral prefrontal cortex and deficits in the caudate and anterior cingulate cortex respectively [7]. Emotional blunting, on the other hand, is more likely related to deficits in the orbito-medial prefrontal cortex and the ventral striatum [7]. Since these apathy dimensions have different underlying pathologies, they may also be differentially associated with other clinical aspects of the disease. These associations may have implications for how the syndrome impacts on such factors as carer burden, disability, and QoL.

The objective of the present study was to explore the relationship between apathy, with and without the specific dimension of emotional blunting, and specific demographic and clinical factors, including psychiatric and neuropsychological variables. The presence of clinically significant apathy and its specific dimensions was ascertained using the Apathy Inventory (IA).

\section{Methods}

All participants had the capacity to provide informed consent for the study and all procedures were approved by the local ethics committee.

\section{Participants}

A total of 91 PD participants meeting UK Brain Bank criteria, were consecutively, and by request, recruited from neurology clinics in the North West of England [8]. Those with Mini-mental State Exam 
Citation: Leroi I, Perera N, Harbishettar V, Robert P (2014) Apathy and Emotional Blunting in Parkinson's Disease. Brain Disord Ther 3: 141.

Page 2 of 8

(MMSE) of $<25$ and meeting research and pragmatic criteria for dementia in PD, were excluded from the study $[9,10]$. The study sample was initially divided into two groups: (1) those with clinically significant apathy $(n=32)$; and (2) those without apathy $(n=59)$. Subsequently, within the apathy group, $\mathrm{n}=22$ were identified as having clinically significant emotional blunting $(\mathrm{EB}+)$ and $\mathrm{n}=10$ were identified as having apathy without emotional blunting (diminished interest and/or initiative only; EB-). These latter two groups were also compared to those without apathy $(n=59)$. All assessments were done during the "on" medication state. Each PD participant had a caregiver who participated in the study. The caregivers were all spouses or adult children and had atleast weekly contact with the PD participant.

\section{Ascertainment of apathy}

The Apathy Inventory (IA) evaluates the syndrome based on three underlying dimensions which were of interest to the study: emotional blunting, diminished interest and diminished initiative. As a gold standard for determining the presence of clinically significant apathy does not yet exist, the IA was validated using an alternative method based on the 'Composite Reference Standard' [11] with the Apathy Scale [12] as the imperfect reference standard, the Neuropsychiatric Inventory apathy subscale (NPI-A) as the first resolver and apathy item of the Unified Parkinson Disease Rating Score (UPDRS-A) as second resolver. This validation method revealed that the IA had a sensitivity of $79 \%$ and a specificity of $94 \%$. Thus, the IA was found to be sensitive and highly specific instrument with a cut-off score of $2 / 3$ for clinically significant apathy. The IA was also shown to have good concurrent validity with the other recommended apathy rating instruments such as Apathy Scale, NPI-A and UPDRS-A [13].

\section{Assessment of clinical characteristics}

Disease characteristics were assessed as per the Unified Parkinson's Disease Rating Scale (UPDRS), part III (rated during the "on" medication state) and the Hoehn-Yahr (HY) scale. The Levodopa equivalent daily dose (LEDD) was calculated using a previously reported formula [14-16].

\section{Psychiatric and cognitive assessment}

Anxiety and depression were assessed with the self-rated Hospital Anxiety and Depression Scale (HADS) [17]. A cognitive test battery with a focus on executive function was administered as outlined in Table 1.

\begin{tabular}{|c|c|c|}
\hline Cognitive domain & $\begin{array}{c}\text { Assessment } \\
\text { instrument }\end{array}$ & Reference \\
\hline Global cognition & $\begin{array}{l}\text { Mini-Mental State } \\
\text { Examination (MMSE) }\end{array}$ & Folstein et al. [R1] \\
\hline Verbal fluency & FAS task & Tombaugh et al. [R2] \\
\hline $\begin{array}{l}\text { Concept acquisition and } \\
\text { set shift }\end{array}$ & $\begin{array}{l}\text { modified Wisconsin } \\
\text { Card Sorting Task } \\
\text { (mWCST) }\end{array}$ & Lineweaver et al. [R3] \\
\hline $\begin{array}{l}\text { Attentional shift, visual } \\
\text { scanning and } \\
\text { psychomotor speed }\end{array}$ & $\begin{array}{l}\text { Trail Making A and B } \\
\text { (TMT-A and TMT-B) }\end{array}$ & $\begin{array}{ll}\text { Army Individual } & \text { Test } \\
\text { Battery. (1944) [R4] } & \end{array}$ \\
\hline Working memory & n-back & Owen et al. [R5] \\
\hline $\begin{array}{l}\text { Premorbid cognitive } \\
\text { ability }\end{array}$ & $\begin{array}{l}\text { National Adult Reading } \\
\text { Test, (NART) }\end{array}$ & Blair and Spree [R6] \\
\hline
\end{tabular}

Table 1: Outline of the cognitive test battery used in the study, emphasising executive function

\begin{tabular}{|c|c|c|c|c|}
\hline Variable of interest & Non-apathy $(n=59)$ & Apathy $(n=32)$ & $\begin{array}{l}\text { Test statistic } \\
\text { (t-test/ Mann- Whitney) }\end{array}$ & p-value; ( $95 \%$ confidence intervals) \\
\hline & \multicolumn{2}{|l|}{ Mean (SD); median* } & & \\
\hline \multicolumn{5}{|c|}{ Demographic variables: } \\
\hline Age (years) & $62.34(10.67)$ & $66.09(10.44)$ & $t=--2.04$ & $\begin{array}{l}0.07 \\
(-9.38 ; 0.12)\end{array}$ \\
\hline Education (years) & $13.61(2.71)$ & $13.25(2.31)$ & $t=-0.64$ & $\begin{array}{l}0.52 \\
(-0.77 ; 1.49)\end{array}$ \\
\hline Pre-morbid IQ & $111.81(12.21)$ & $112.29(8.23)$ & $t=--0.20$ & $\begin{array}{l}0.85 \\
(-5.33 ; 4.38)\end{array}$ \\
\hline \multicolumn{5}{|l|}{ Disease variables: } \\
\hline Age of onset (years) & $55.21(11.86)$ & $58.72(11.26)$ & $t=--1.36$ & $\begin{array}{l}0.23 \\
(-8.39 ; 2.03)\end{array}$ \\
\hline $\begin{array}{l}\text { Duration of disease } \\
\text { (months) }\end{array}$ & $89.89(66.04)$ & $105.56(67.04)$ & $t=--1.07$ & $\begin{array}{l}0.29 \\
(-44.82 ; 13.48)\end{array}$ \\
\hline Hoehn-Yahr stage & $2.21(0.62)$ & $2.59(0.76)$ & $t=--2.59$ & $0.01(-.09 ;-.07)$ \\
\hline
\end{tabular}


Citation: Leroi I, Perera N, Harbishettar V, Robert P (2014) Apathy and Emotional Blunting in Parkinson's Disease. Brain Disord Ther 3: 141.

Page 3 of 8

\begin{tabular}{|c|c|c|c|c|}
\hline UPDRS motor & $27.01(11.36)$ & $32.13(11.98)$ & $t=--1.97$ & $0.06(-10.42 ; .19)$ \\
\hline LEDD & $707.37(492.44)$ & $697.15(94.08)$ & $\mathrm{t}=-1.83$ & $0.07(-477.06 ; 37.09)$ \\
\hline $\begin{array}{l}\text { Tremor/postural-instability gait } \\
\text { ratio }\end{array}$ & $1.22(1.71)$ & $0.61(0.90)$ & $\mathrm{t}=2.16$ & $0.03(0.28 ; .05)$ \\
\hline \multicolumn{5}{|c|}{ Apathy dimensions from the Apathy Inventory (IA): } \\
\hline IA-Emotional blunting & $0.34(0.18)$ & $4.31(4.28)$ & $t=-5.65$ & $<0.001(-5.82 ;-2.73)$ \\
\hline IA-Initiative & $0.02(0.13)$ & $6.31(4.27)$ & $t=-8.34$ & $<0.001(-7.83 ;-4.76)$ \\
\hline IA-Interest & $0.17(0.13)$ & $6.56(3.71)$ & $\mathrm{t}=-9.99$ & $<0.001(-7.88:-5.21)$ \\
\hline \multicolumn{5}{|c|}{ Psychiatric and cognitive variables: } \\
\hline $\begin{array}{l}\text { HADS } \\
\text { depression }\end{array}$ & $4.52(2.96)$ & $8.66(3.62)$ & $t=-5.86$ & $<0.001(-5.53 ;-2.73)$ \\
\hline $\begin{array}{l}\text { HADS } \\
\text { anxiety }\end{array}$ & $5.91(5.89)$ & $8.19(5.99)$ & $t=-0.96$ & $0.34(-2.62 ; 0.89)$ \\
\hline MMSE Total & $\begin{array}{l}28.78(1.46) ; \\
29.00\end{array}$ & $\begin{array}{l}28.00(1.77) \\
29.00\end{array}$ & $\mathrm{U}=822.00$ & $0.26(-0.16 ; 0.84)$ \\
\hline Working memory (n-back) & $\begin{array}{l}16.49(3.43) \\
16.50\end{array}$ & $\begin{array}{l}14.41(4.02) \\
15.00\end{array}$ & $\mathrm{U}=615.50$ & $0.03(0.37 ; 3.66)$ \\
\hline $\begin{array}{l}\text { Verbal fluency } \\
\text { (FAS) }\end{array}$ & $\begin{array}{l}37.11(12.97) ; \\
39.00\end{array}$ & $\begin{array}{l}32.47(12.88) \\
38.50\end{array}$ & $U=776.00$ & $0.20(-1.67 ; 9.23)$ \\
\hline 5-minute recall & $\begin{array}{l}2.64(0.69) ; \\
3.00\end{array}$ & $\begin{array}{l}2.31(0.88) ; \\
3.00\end{array}$ & $U=736.00$ & $0.06(-.03 ; 0.69)$ \\
\hline $\begin{array}{l}\text { Attentional shift } \\
\text { (TMT B-TMT A) }\end{array}$ & $\begin{array}{l}75.56(65.48) ; \\
52.50\end{array}$ & $\begin{array}{l}\text { 110.78(76.73); } \\
91.50\end{array}$ & $\mathrm{U}=668.50$ & $0.02(-68.12 ;-3.58)$ \\
\hline $\begin{array}{l}\text { Set-shifting } \\
\text { (mWCST Total) }\end{array}$ & $\begin{array}{l}37.07(8.44) \\
37.00\end{array}$ & $\begin{array}{l}33.07(9.07) \\
36.00\end{array}$ & $U=629.50$ & $0.30(0.25 ; 8.14)$ \\
\hline \multicolumn{5}{|l|}{ Impact variables: } \\
\hline $\begin{array}{l}\text { Disability } \\
\text { (UPDRS-ADL) }\end{array}$ & $13.20(5.30)$ & $17.44(4.06)$ & $t=-3.92$ & $<0.001(-6.34 ;-2.07)$ \\
\hline $\begin{array}{l}\text { Disability } \quad \text { (Schwab and } \\
\text { England) }\end{array}$ & $81.43(9.76)$ & $68.28(14.73)$ & $t=5.12$ & $<0.001(8.13 ; 18.46)$ \\
\hline Quality of life (PDQ-8) & $16.67(10.07)$ & $25.13(10.07)$ & $t=-3.76$ & $<0.001(-12.70 ;-3.92)$ \\
\hline Zarit Burden Inventory & $18.06(12.77)$ & $29.03(14.43)$ & $t=-3.45$ & $<0.001(-17.32 ;-4.62)$ \\
\hline
\end{tabular}

Table 2: Comparison of means (SD) and proportions of demographic and clinical characteristics of the apathy and the non-apathy PD groups. ${ }^{1}$ National Adult Reading Test (NART); ${ }^{2}$ Unified Parkinson's Disease Rating Scale; ${ }^{3}$ Levodopa equivalent daily dose; ${ }^{4}$ Derived from UPDRS; items ; ${ }^{5}$ Hospital Anxiety and Depression Scale; ${ }^{6}$ Mini-Mental State Exam; ${ }^{7}$ Trail Making Test B-Trail Making Test A; ${ }^{8}$ Modified Wisconsin; Card Sorting Test; ${ }^{9}$ Parkinson's Disease Quality of Life-8 scale. ${ }^{\star}$ for non-normally distributed data

\section{Assessment of impact}

Disability was measured in two ways: (1) the UPDRS-Activities of Daily living sub-scale (UPDRS-ADL), which rates the ability to carry out daily tasks; and (2) the Schwab and England scale, which is a global measure of independence and ADL performance [17,18]. Healthrelated quality of life (QoL) was measured using single index score of the Parkinson's Disease Quality of Life Scale-8 item version (PDQ-8) which is a validated abbreviated version of the PDQ-39 [19]. Finally, caregiver burden was measured using the Zarit Burden Inventory (ZBI) which rates the impact on the caregivers' physical, emotional and socioeconomic status [20]. 


\section{Analysis}

All data were analysed using SPSS version 16. Exploratory analysis of the data revealed that the variables were both normally and nonnormally distributed. Thus, both independent $t$ tests and MannWhitney tests were performed to compare group differences on the variables of interest. Three-way comparisons were undertaken with either ANOVA or Kruskall-Wallis. All group comparisons were two tailed unless for non-parametric comparisons of non-normally distributed data, where a one-tail test was used. Finally, bivariate (Pearson/Spearman) correlation were undertaken to explore associations among clinical variables and: (1) the IA emotional blunting sub-score alone; and (2) the IA initiation and interest subscores combined (to indicate apathy without emotional blunting).

\section{Results}

For the entire group of 91 participants, the mean age was 63.23 (SD 10.67 ) years with a range of 36 to 80 . Seventy percent of the sample was male, and the mean duration of PD was 93.87 months (SD 65.85) months. The mean age at onset of PD motor symptoms was 55.39 (SD 11.58) years and the mean Hoehn-Yahr score was 2.31 (SD 0.7) with a range of stages 1 to 4 . Within the group of caregivers, 59\% was male, with a mean age of 63.81 (SD 11.21) years. The PD participants were acquainted with their caregivers for a mean length of time of 38.67 (SD 13.20) years.

The mean total IA score for the entire group was 6.09 (SD 10.16) with the dimension sub-scores as follows: emotional blunting, 1.53 (SD 3.25); lack of initiative, 2.23 (SD 3.93); and lack of interest, 2.23 (SD 3.82). Within the apathy group, $\mathrm{n}=22(68.8 \%)$ endorsed clinically significant emotional blunting ( $\mathrm{EB}+)$; and $\mathrm{n}=10$ (31.2\%) endorsed apathy without emotional blunting (lack of or diminished initiative and/or interest only; EB-).

\section{Group comparison: Apathy and non-apathy}

As is shown in Table 2, there were no significant differences found between the apathy group and those without apathy in terms of age, pre-morbid IQ and years of education. The mean AI total score in the apathy group was 17.18 (SD 0.17) compared to those without apathy, which was 0.07 (SD 0.41) $(\mathrm{p}<0.001 ; 95 \% \mathrm{CI}$ of -20.78 to -13.45$)$. Disease variables, including age of disease onset, duration of disease, UPDRS motor score, and dopaminergic load (LEDD) also did not differ between groups. Key differences did, however, emerge on tremor/postural gait instability ratio, which revealed that those with apathy were less tremor-dominant than the non-apathy group $(\mathrm{p}=0.03)$, as well as Hoehn-Yahr stage of disease being more advanced in the apathy group $(\mathrm{p}=0.01)$. Differences in psychiatric burden were noted in that the apathy group was more depressed (HADSDepression; HADS-D; $\mathrm{p}<0.001$ ) however level of anxiety (HADSanxiety; HADS-A) did not differ between groups. Cognitively, the apathy group was significantly worse on working memory (n-Back; $\mathrm{p}=0.03$ ) and attentional shift (TMT_B - TMT_A; $\mathrm{p}=0.02$ ).

The impact of the apathy group was significantly greater compared to those without apathy on all outcomes: disability (UPDRS-ADL, $\mathrm{p}<0.001$; Schwab and England, $\mathrm{p}<0.001$ ); and QoL (PDQ-8, $\mathrm{p}<0.001$ ). The impact on caregiver burden was also significantly greater in the apathy group compared to the non-apathy group $(\mathrm{p}=0.001)$. These data are shown on Table 2.

\begin{tabular}{|c|c|c|c|c|}
\hline Variable of interest & $\begin{array}{l}\text { Non-apathy } \\
(n=59)\end{array}$ & $\begin{array}{l}\text { Apathy + emotional } \\
\text { blunting } \\
(n=22)\end{array}$ & $\begin{array}{l}\text { Apathy - emotional } \\
\text { blunting } \\
(n=10)\end{array}$ & $\begin{array}{l}\text { Test statistic } \\
\text { (F value if ANOVA/Kruskall- } \\
\text { Wallis); } \\
\text { (p-value) }\end{array}$ \\
\hline & \multicolumn{3}{|c|}{ Mean (SD); median* } & \\
\hline \multicolumn{5}{|l|}{ Demographic variables: } \\
\hline Age (years) & $61.39(10.58)$ & $63.81(10.64)$ & $71.10(8.45)$ & $\begin{array}{l}F=4.04 ; 0.02 a \\
(95 \% \text { Cl: } 60.77 ; 65.29)\end{array}$ \\
\hline Education (years) & $\begin{array}{l}13.61(2.71) \\
12.00\end{array}$ & $\begin{array}{l}13.32(2.63) ; \\
12.00\end{array}$ & $\begin{array}{l}13.10(1.52) ; \\
12.00\end{array}$ & 0.78 \\
\hline Pre-morbid IQ & $111.81(12.21)$ & $112.05(8.95)$ & $111.82(10.92)$ & $\begin{array}{l}F=0.06 ; 0.94 \\
(95 \% \text { Cl: } 17.51 ; 22.02)\end{array}$ \\
\hline \multicolumn{5}{|l|}{ Disease variables: } \\
\hline Age of onset (years) & $55.21(11.86)$ & $54.59(11.84)$ & $62.10(9.05)$ & $\begin{array}{l}\mathrm{F}=2.10 ; 0.13 \\
(95 \% \mathrm{Cl}: 52.39 ; 57.40)\end{array}$ \\
\hline $\begin{array}{l}\text { Duration of disease } \\
\text { (months) }\end{array}$ & $\begin{array}{l}89.89(66.04) ; \\
72.00\end{array}$ & $\begin{array}{l}\text { 104.45(71.86); } \\
93.00\end{array}$ & $\begin{array}{l}\text { 108.00(58.51); } \\
90.00\end{array}$ & 0.46 \\
\hline Hoehn-Yahr & $2.21(0.62)$ & $2.45(0.69)$ & $2.90(0.84)$ & $\begin{array}{l}F=4.74 ; 0.01 a \\
(95 \% \mathrm{Cl}: 2.20 ; 2.49)\end{array}$ \\
\hline UPDRS motor & $\begin{array}{l}27.01(3.27) \\
27.00\end{array}$ & $\begin{array}{l}30.05(12.41) ; \\
27.50\end{array}$ & $\begin{array}{l}36.30(10.44) ; \\
34.50\end{array}$ & $0.01 a$ \\
\hline
\end{tabular}


Citation: Leroi I, Perera N, Harbishettar V, Robert P (2014) Apathy and Emotional Blunting in Parkinson's Disease. Brain Disord Ther 3: 141.

Page 5 of 8

\begin{tabular}{|c|c|c|c|c|}
\hline $\begin{array}{l}\text { Tremor/postural-instability gait } \\
\text { index }\end{array}$ & $1.20(1.72)$ & $0.52(0.97)$ & $0.77(0.78)$ & $\begin{array}{l}\mathrm{F}=1.58 ; 0.21 \\
(95 \% \mathrm{Cl}: 0.69 ; 1.33)\end{array}$ \\
\hline LEDD & $\begin{array}{l}707.37 \\
(492.44) \\
719.00\end{array}$ & $\begin{array}{l}893.81 \\
(644.24) \\
796.00\end{array}$ & $\begin{array}{l}968.47 \\
(605.05): \\
750.00\end{array}$ & 0.39 \\
\hline \multicolumn{5}{|l|}{ Psychiatric and cognitive variables: } \\
\hline Apathy Inventory & $0.07(0.41)$ & $19.55(10.75)$ & $12.00(6.57)$ & $\begin{array}{l}F=99.08 ;<0.001 a, b, c \\
(95 \% \mathrm{Cl}:-0.12 ; 0.03)\end{array}$ \\
\hline $\begin{array}{l}\text { HADS } \\
\text { anxiety }\end{array}$ & $\begin{array}{l}5.91(5.89) ; \\
5.00\end{array}$ & $\begin{array}{l}6.82(4.32) ; \\
7.50\end{array}$ & $\begin{array}{l}5.20(2.82) ; \\
5.00\end{array}$ & 0.39 \\
\hline $\begin{array}{l}\text { HADS } \\
\text { depression }\end{array}$ & $\begin{array}{l}4.52(2.96) ; \\
4.50\end{array}$ & $\begin{array}{l}9.00(3.35) ; \\
9.00\end{array}$ & $\begin{array}{l}7.90(4.25) ; \\
10.00\end{array}$ & $<0.001 a, b$ \\
\hline MMSE Total & $\begin{array}{l}28.78(1.46) \\
29.00\end{array}$ & $\begin{array}{l}28.23(1.74) \\
29.00\end{array}$ & $\begin{array}{l}27.50(1.90) \\
28.00\end{array}$ & 0.10 \\
\hline $\begin{array}{l}\text { Working memory } \\
\text { (n-back) }\end{array}$ & $\begin{array}{l}16.49(3.43) \\
16.00\end{array}$ & $\begin{array}{l}14.38(4.59) \\
15.00\end{array}$ & $\begin{array}{l}14.20(2.13) ; \\
14.00\end{array}$ & 0.18 \\
\hline Verbal fluency (FAS) & $\begin{array}{l}37.11(12.97) ; \\
36.00\end{array}$ & $\begin{array}{l}32.68(12.29) \\
36.50\end{array}$ & $\begin{array}{l}32.00(14.81) \\
29.00\end{array}$ & 0.80 \\
\hline 5-minute recall & $\begin{array}{l}2.64(0.69) ; \\
3.00\end{array}$ & $\begin{array}{l}2.41(0.67) \\
2.50\end{array}$ & $\begin{array}{l}2.10(1.29) ; \\
3.00\end{array}$ & 0.21 \\
\hline $\begin{array}{l}\text { Attentional shift } \\
\text { (TMT B-TMT A) }\end{array}$ & $\begin{array}{l}75.56(65.48) \\
55.00\end{array}$ & $\begin{array}{l}94.50(7.58) \\
74.00\end{array}$ & $\begin{array}{l}\text { 146.60(81.12); } \\
190.00\end{array}$ & 0.14 \\
\hline $\begin{array}{l}\text { Set-shifting } \\
\text { (MWCST Total) }\end{array}$ & $\begin{array}{l}37.07(8.44) \\
37.00\end{array}$ & $\begin{array}{l}32.86(9.99) \\
34.00\end{array}$ & $\begin{array}{l}33.63(6.61) \\
37.00\end{array}$ & 0.28 \\
\hline \multicolumn{5}{|l|}{ Impact variables: } \\
\hline Disability (UPDRS-ADL) & $13.20(5.30)$ & $17.27(4.19)$ & $17.80(3.97)$ & $\begin{array}{l}F=7.63 ;<0.001 a, b \\
(95 \% \mathrm{Cl}: 13.64 ; 15.85)\end{array}$ \\
\hline Disability (Schwab-England) & $81.43(9.76)$ & $69.55(16.40)$ & $65.5(10.39)$ & $\begin{array}{l}F=13.02 ;<0.001 a, b \\
(95 \% \text { Cl: } 73.98 ; 79.61)\end{array}$ \\
\hline Quality of life (PDQ-8) & $16.67(10.07)$ & $27.27(10.08)$ & $20.42(8.72)$ & $\begin{array}{l}\mathrm{F}=9.07 ;<0.001^{\mathrm{b}} \\
(95 \% \mathrm{Cl}: 17.51 ; 22.02)\end{array}$ \\
\hline Caregiver burden (Zarit) & $18.06(12.77)$ & $30.15(12.72)$ & $26.56(18.28)$ & $\begin{array}{l}F=6.12 ; 0.004^{b} \\
(95 \% \text { Cl: } 18.99 ; 25.61)\end{array}$ \\
\hline
\end{tabular}

Table 3: Comparison of means (SD) and proportions of demographic and clinical characteristics of the apathy groups with and without emotional blunting and the non-apathy groups. ${ }^{1}$ National Adult Reading Test (NART); ${ }^{2}$ Unified Parkinson's Disease Rating Scale; ${ }^{3}$ Derived from UPDRS items. ${ }^{4}$ Levodopa equivalent daily dose; ${ }^{5}$ Hospital Anxiety and Depression Scale; ${ }^{6}$ Mini-Mental State Exam; ${ }^{7}$ Trail Making Test BTrail Making Test A; ${ }^{8}$ Modified Wisconsin Card Sorting Test; ${ }^{9}$ Parkinson's Disease Quality of Life-8 scale. Post-hoc Scheffe or Mann Whitney $\mathrm{U}$ for two-group comparison: ${ }^{\mathrm{a}} \mathrm{EB}$ - vs non-apathy at $\mathrm{p}<0.05$; ${ }^{\mathrm{b}} \mathrm{EB}+\mathrm{vs}$ non-apathy at $\mathrm{p}<0.05$; ${ }^{\mathrm{c}} \mathrm{EB}+$ versus $\mathrm{EB}-$ at $\mathrm{p}<0.05$. ${ }^{\star}$ for non-normally distributed data

\section{Group comparison: EB+, EB-, and non-apathy}

As shown in Table 3, the mean IA total score was significantly greater in both the EB+ and EB- groups compared to those without apathy $(\mathrm{p}<0.001)$. The two sub-groups also differed significantly from each other $(\mathrm{p}=0.02)$ with $\mathrm{EB}+$ having a greater burden of apathy due to the added dimension of emotional blunting. The three groups did not differ on age of disease onset, duration of disease, tremor-dominance or dopaminergic load (LEDD). There were also no differences across the three groups on level of anxiety, verbal fluency, working memory, 5 -minute recall and set-shifting. 
Page 6 of 8

The EB- group, compared to the non-apathy group was significantly different in that the former was older $(\mathrm{p}=0.03)$, had a later disease stage (Hoehn-Yahr, $\mathrm{p}=0.01$ ), and more severe motor function (UPDRS motor, $\mathrm{p}=0.01$ ). Cognitively, the groups did not differ in any of the domains although the EB+ group scored worse on self-rated depression. In contrast, the EB+ group did not differ from the nonapathy group on demographic, disease or cognitive variables, but was also significantly more depressed compared to the non-apathy group. These data are shown in Table 3. Finally, on disease, psychiatric and cognitive factors, there were no significant differences between the EB + and the EB groups. Wisconsin Card Sorting Test. With regards to the impact variables (Table 3), both apathy groups (EB+ and EB-) had significantly greater disability levels (UPDRS-ADL score, $\mathrm{p}<.001$; Schwab-England score, $\mathrm{p}<0.001)$ compared to the non-apathy group. This difference was apparent with the EB+ group despite having no difference in stage of $\mathrm{PD}$, motor severity or other key disease variables.
The EB+ group also had more impaired QoL $(\mathrm{p}<0.001)$ and greater impact on caregiver burden $(\mathrm{p}=0.03)$ compared to the non-apathy group. In contrast, the EB- group did not differ from the non-apathy group on either QoL or carer burden.

\section{Correlation analysis}

The IA emotional blunting sub-score correlated with depression score on the HADS-D $(\rho=0.46 ; p<0.001)$ and did not correlate with any of the demographic, clinical, or cognitive variables nor level of anxiety. The combined IA initiation and interest sub-scores correlated with several variables, including age, age of disease onset, motor severity, level of depression and cognitive scores (MMSE, attentional shift and working memory) (Table 4). There was no significant correlation between this combined score and disease duration, level of anxiety, verbal fluency or set-shifting.

\begin{tabular}{|c|c|c|c|c|}
\hline & Age & Levodopa daily equivalents & Age of disease onset & Duration of disease \\
\hline \multirow{5}{*}{$\begin{array}{l}\text { Apathy Inventory } \\
\text { initiation + interest } \\
\text { sub-scores } \\
\text { combined }\end{array}$} & $0.32^{\star \star *}$ & 0.05 & $0.29^{\star \star}$ & 0.01 \\
\hline & UPDRS1 motor & HADS2-anxiety & HADS2-depression & MMSE3 total \\
\hline & $0.22^{\star *}$ & -0.07 & $0.50^{\star * *}$ & $-0.33^{* *}$ \\
\hline & Verbal fluency (FAS) & $\begin{array}{l}\text { Working memory } \\
\text { (n-back) }\end{array}$ & Attentional shift (TMT_B-TMT_A4) & $\begin{array}{l}\text { Set-shifting } \\
\text { (modified WCST5) }\end{array}$ \\
\hline & -0.20 & $-0.27^{\star \star}$ & $-0.27^{* *}$ & -0.24 \\
\hline
\end{tabular}

Table 4: Correlation matrix between apathy score without emotional blunting (initiation + interest sub-scores on the Apathy Inventory) and demographic, clinical, psychiatric and cognitive variables. ${ }^{*} \mathrm{p}<0.05 ;{ }^{* *} \mathrm{p}<0.01 ;{ }^{* * *} \mathrm{p}<0.001$ : 1Unified Parkinson's Disease Rating Scale; 2 Hospital Anxiety and Depression Scale; 3Mini-mental State Exam; 4Trail Making Test B-Trail Making Test A; 5Modified

\section{Discussion}

This study is one of the few in PD to examine individual dimensions of apathy in a participant sample free of dementia, with particular emphasis on emotional blunting. Since apathy is a syndrome comprised of distinct dimensions with different neuroanatomical underpinnings, examining the clinical associations of individual dimensions is important and of interest [5]

Within our PD sample, 35\% of the participants had a diagnosis of apathy according to the IA. These results are comparable to previous studies in PD, some of which have also included participants with dementia $[3,21]$. The link between apathy and cognitive impairment, particularly executive dysfunction and dementia, is well recognised and in our sample, those with apathy had more impaired executive function, in spite of being free of dementia [22]. In particular, those with apathy performed worse on tasks of working memory and attentional shift. This mirrors previous findings in PD and suggests that cognitive and motivational disturbances share a common underlying pathophysiology [1,5].

The dimension of emotional blunting has particular relevance in PD since dopamine is associated with emotion and reward processing. Within our entire apathy sample, $69 \%(n=22)$ manifested emotional blunting as well as loss of initiation and/or interest, suggesting that this dimension of apathy in PD is common but not ubiquitous and may not occur in isolation.

Both the EB+ and the EB- apathy groups displayed higher levels of depression than the non-apathy PD participants. The overlap between apathy and depression in PD is well recognised and likely relates to common deficits in fronto-limbic dopaminergic pathways [4,23]. Despite the existence of this co-morbidity, several studies have identified a dissociation between apathy and depression [24]. Contrary to expectation, those in the EB+ group did not report lower levels of depression however this could have related to the accompanying loss of interest and/or initiative which, in this study, could not be parsed out.

In our study, apathy in PD was found to impact significantly on levels of disability and QoL. In spite of similar levels of motor severity, duration of disease, and dopaminergic load between the two groups, disability was much greater in those with apathy, even though they were free of dementia. The PD patient with apathy is generally more inactive compared to those with non-apathy PD and this passivity can lead to further functional decline and greater levels of debilitation $[3,6,25]$. A possible explanation for this finding is that depression may be contributing to disability. In a study of male PD sufferers, it was found found that $37 \%$ of the variance in the UPDRS ADL score was accounted for by severity of depression and worsening cognition, and $54 \%$ of the variance in Schwab and England score was accounted for by the same two factors plus increasing severity of PD [26]. The impact of apathy on QoL is not surprising as apathy has previously been shown to be strongly associated with worse QoL and may also be related to the higher levels co-morbid depression in the apathy group, another factor associated with impairment in QoL [27]. Caregiver burden in PD without dementia has previously been examined by our group in a cohort of 71 patient-caregiver dyads, and as in the current 
study, we found that apathy in PD without dementia was associated with greater levels of caregiver burden [28].

It is noteworthy in our study that the EB+ group had lower QoL and greater caregiver burden compared to the EB- group, despite the latter group being associated with markers of more advanced disease (greater motor severity, higher Hoehn-Yahr stage and older age) as well as having a higher overall burden of apathy. This suggests that the dimension of emotional blunting has significant consequences for both PD patients and their caregivers and should be identified and managed as a symptom separate from the apathy syndrome. An alternative explanation is that those in the EB- group may not have had true apathy after all. Rather, markers of more advanced disease and older age may be masquerading as apathy. In contrast, "true" apathy in PD may involve emotional blunting with its concomitant impact on such measures as QoL and caregiver burden.

Limitations to the current study include the relatively small sample, particularly when examining subgroups within the apathy cohort. The study was also limited by its cross-sectional nature, which limits the conclusions that can be drawn regarding associations with apathy and emotional blunting. Furthermore, the cross-sectional nature of the study means that the conclusions regarding associations between apathy and emotional blunting should be approached with some caution. This was not possible in the current study since all those with emotional blunting also had impairment in at least one other apathy dimension. Further work needs to be undertaken to determine whether this pattern of apathy is typical in PD compared to other neurodegenerative conditions such as Alzheimer disease in which it has been possible to demonstrate separate dimensions [29]. In spite of these limitations, this study is unique due its examination of different apathy dimensions in a PD participant group without dementia. In the future, it will be of interest to use objective measures, such as the startle reflex, to assess apathy dimensions, in order to further elucidate underlying pathophysiology and clinical associations [30].

Apathy should be recognised early, and differentiated from depression, to avoid unnecessary treatment of depression. If apathy is identified, the affected patient's PD treatment may need to be reviewed to include an optimisation of dopaminergic agonist medications [31]. Counselling patient and family members may help to overcome the ongoing caregiver burden although the efficacy of these types of interventions is still developing, including other 'psychosocial' interventions such cognitive training, cognitive rehabilitation/ stimulation and exercise programs [32].

In conclusion, this study confirms that apathy in $\mathrm{PD}$, even in the absence of dementia, is associated with higher levels of disability, greater impairment in QoL and greater caregiver burden. Emotional blunting is an important dimension of apathy, which, when added to underlying loss of initiative and/or interest can impact even more on QoL and caregiver burden. These findings underscore the importance of systematically screening for apathy in PD, particularly emotional blunting.

\section{References}

1. Dujardin K, Sockeel P, Devos D, Delliaux M, Krystkowiak P, et al. (2007) Characteristics of apathy in Parkinson's disease. Mov Disord 22: 778-784.

2. Leroi I, Harbishettar V, Andrews M, McDonald K, Byrne EJ, et al. (2012) Carer burden in apathy and impulse control disorders in Parkinson's disease. Int J Geriatr Psychiatry 27: 160-166.
3. Dujardin K, Sockeel P, Delliaux M, Destée A, Defebvre L (2009) Apathy may herald cognitive decline and dementia in Parkinson's disease. Mov Disord 24: 2391-2397.

4. Robert PH, Clairet S, Benoit M, Koutaich J, Bertogliati C, et al. (2002) The apathy inventory: assessment of apathy and awareness in Alzheimer's disease, Parkinson's disease and mild cognitive impairment. Int J Geriatr Psychiatry 17: 1099-1105.

5. Levy R, Dubois B (2006) Apathy and the functional anatomy of the prefrontal cortex-basal ganglia circuits. Cereb Cortex 16: 916-928.

6. Levy R, Czernecki V (2006) Apathy and the basal ganglia. J Neurol 253 Suppl 7: VII54-61.

7. Benoit M, Koulibaly PM, Migneco O, Darcourt J, Pringuey DJ et al. (2002). Brain perfusion in Alzheimer's disease with and without apathy: A SPECT study with statistical parametric mapping analysis. Psychiatry Research 114: 103-111.

8. Hughes AJ, Daniel SE, Kilford L, Lees AJ (1992) Accuracy of clinical diagnosis of idiopathic Parkinson's disease: a clinico-pathological study of 100 cases. J Neurol Neurosurg Psychiatry 55: 181-184.

9. Folstein MF, Folstein SE, McHugh PR (1975): “Mini-Mental State”: a practical method for grading the cognitive state of patients for the clinician. J Psychiatr Res 12: 189-198.

10. Emre M, Aarsland D, Brown R, Burn DJ, Duyckaerts C, et al. (2007) Clinical diagnostic criteria for dementia associated with Parkinson's disease. Mov Disord 22: 1689-1707.

11. Alonzo TA, Pepe MS (1999) Using a combination of reference tests to assess the accuracy of a new diagnostic test. Stat Med 18: 2987-3003.

12. Starkstein SE, Mayberg HS, Preziosi TJ, Andrezejewski P, Leiguarda R, et al. (1992) Reliability, validity, and clinical correlates of apathy in Parkinson's disease. J Neuropsychiatry Clin Neurosci 4: 134-139.

13. Harbishettar V, Leroi I (2014) Validating an Apathy Rating Scale in the absence of a Gold Standard. Gold Standard. Royal Coll Psych, Easter Div Meeting, Cambridge, UK (abstract).

14. Fahn S, Elton RL (1987) UPDRS Development Committee. Unified Parkinson's Disease Rating Scale. In: Fahn S, Marsden CD, Calne DB, Goldstein M, eds. Recent Developments in Parkinson's Disease. Florham Park, NJ: Macmillan: 153-163.

15. Hoehn MM, Yahr MD (1967) Parkinsonism: onset, progression, and mortality. Neurology 17: 427-442.

16. Tomlinson CL, Stowe R, Patel S, Rick C, Gray R, et al. (2010) Systematic review of levodopa dose equivalency reporting in Parkinson's disease. Mov Disord 25: 2649-2653.

17. Zigmond AS, Snaith RP (1983). The hospital anxiety and depression scale Acta Psychiatr Scand 67: 361-370.

18. Schwab R, England A (1969) Project technique for evaluating surgery in Parkinson's disease. In: Gillingham, J., Donaldson, I. (Eds.), Third Symposium on Parkinson's Disease. E\&S Livingstone, Edinburgh, Scotland 152-157.

19. Jenkinson C, Fitzpatrick R, Peto V, Greenhall R, Hyman N (1997) The Parkinson's Disease Questionnaire (PDQ-39): development and validation of a Parkinson's disease summary index score. Age Ageing 26: 353-357.

20. Zarit SH, Orr NK, Zarit JM (1985) The hidden victims of Alzheimer's disease: Families under stress New York University Press, New York.

21. Pedersen KF, Larsen JP, Alves G, Aarsland D (2009) Prevalence and clinical correlates of apathy in Parkinson's disease: a community-based study. Parkinsonism Relat Disord 15: 295-299.

22. Isella V, Melzi P, Grimaldi M, Iurlaro S, Piolti R, et al. (2002) Clinical, neuropsychological, and morphometric correlates of apathy in Parkinson's disease. Mov Disord 17: 366-371.

23. Oguru M, Tachibana H, Toda K, Okuda B, Oka N (2010) Apathy and depression in Parkinson disease. J Geriatr Psychiatry Neurol 23: 35-41.

24. Levy ML, Cummings JL, Fairbanks LA, Masterman D, Miller BL, et al. (1998) Apathy is not depression. J Neuropsychiatry Clin Neurosci 10: 314-319. 
Citation: Leroi I, Perera N, Harbishettar V, Robert P (2014) Apathy and Emotional Blunting in Parkinson's Disease. Brain Disord Ther 3: 141. doi:10.4172/2168-975X.1000141

Page 8 of 8

25. Aarsland D, Marsh L, Schrag A (2009) Neuropsychiatric symptoms in Parkinson's disease. Mov Disord 24: 2175-2186.

26. Weintraub D, Moberg PJ, Duda JE, Katz IR, Stern MB (2004) Effect of psychiatric and other non-motor symptoms on disability in Parkinson's disease. J Am Geriatr Soc 143: 565-576.

27. Schrag A, Jahanshahi M, Quinn N (2000) What contributes to quality of life in patients with Parkinson's disease? J Neurol Neurosurg Psychiatry 69: 308-312.

28. Leroi I, Ahearn DJ, Andrews M, McDonald KR, Byrne EJ, et al. (2011) Behavioural disorders, disability and quality of life in Parkinson's disease. Age Ageing 40: 614-621.
29. Benoit M, Clairet S, Koulibaly PM, Darcourt J, Robert PH (2004) Brain perfusion correlates of the apathy inventory dimensions of Alzheimer's disease. Int J Geriatr Psychiatry 19: 864-869.

30. Miller KM, Okun MS, Marsiske M, Fennell EB, Bowers D (2009) Startle reflex hyporeactivity in Parkinson's disease: an emotion-specific or arousal-modulated deficit? Neuropsychologia 47: 1917-1927.

31. Kaji Y, Hirata K (2011) Apathy and anhedonia in Parkinson's disease. ISRN Neurol 2011: 219427.

32. Sindhi A, Leroi I (2013) Non pharmacological therapies for cognitive enhancement in Parkinson's disease: Applying old interventions in a new setting? Neurodegenerative Disease Management 3: 539-547. 